\title{
Impact of variants in ATP-binding cassette transporters on breast cancer treatment
}

\author{
Qingyang Xiao' ${ }^{(D)}$, Yitian Zhou ${ }^{1} \&$ Volker M Lauschke*,1 \\ 1 Department of Physiology \& Pharmacology, Karolinska Institutet, 171 77, Stockholm, Sweden \\ *Author for correspondence: Tel.: +46 852487 711; volker.lauschke@ki.se
}

There has been substantial interest in the impact of ATP-binding cassette (ABC) transporter variability on breast cancer drug resistance. Here, we provide a systematic review of $A B C$ variants in breast cancer therapy. Notably, most studies used small heterogeneous cohorts and their identified associations lack statistical stringency, replication and mechanistic support. We conclude that commonly studied $A B C$ polymorphisms are not suitable to accurately predict therapy response or toxicity in breast cancer patients and cannot guide treatment decisions. However, recent research shows that $A B C$ transporters harbor a plethora of rare variants with individually small effect sizes, and we argue that a shift in strategy from target variant interrogation to comprehensive profiling might hold promise to drastically improve the predictive power of outcome models.

First draft submitted: 24 July 2020; Accepted for publication: 25 September 2020; Published online: 23 November 2020

Keywords: anthracyclines $\bullet$ chemotherapy $\bullet$ drug resistance $\bullet$ drug transporters $\bullet$ personalized medicine $\bullet$ pharmacogenetics $\bullet$ precision oncology $\bullet$ taxanes

Breast cancer constitutes the most prevalent type of malignancy in women and is the leading cause of cancer death accounting for $15 \%$ of cancer mortality among women globally $[1,2]$. Breast cancer is a heterogeneous disease that can be stratified by their molecular and histological features into different subtypes. Histologically, cancers can be distinguished by site into ductal and lobular carcinomas and by stage into pre-invasive and invasive subtypes. The most important molecular determinants are levels of the hormone receptors ER (estrogen receptor) and PR (progesterone receptor), amplification of ERBB2 (encoding HER2) and mutations in the tumor suppressor genes $B R C A 1$ or $B R C A 2$. For a detailed and updated overview of the molecular events underlying breast cancer ontogeny of the different types, we refer the reader to excellent previous reviews and the references therein [3].

Integration of these histological and molecular features gives rise to clinically distinct and therapeutically actionable subtypes (Figure 1). Luminal-like types are hormone receptor-positive (ER and/or PR) without HER2 activation and are treated by endocrine therapy, such as tamoxifen or aromatase inhibitors, with or without adjuvant chemotherapy depending on the level of proliferation. By contrast, HER2 positive cancers are treated using chemotherapy plus HER2 inhibitors (trastuzumab with or without pertuzumab). Treatment recommendations for triple-negative cancers are chemotherapy with potential addition of platinum-based agents. Furthermore, the use of PARP inhibitors (olaparib or talazoparib) is an additional option for patients with BRCA mutations [4,5]. Chemotherapeutic regimens are primarily based on anthracyclines, taxanes and cyclophosphamide [6].

However, while treatment based on molecular features rather than overall tumor burden has drastically improved patient outcomes, drug resistance remains one of the major challenges in breast cancer therapy, particularly for advanced disease. Breast cancer drug resistance is caused by a variety of mechanisms of which increased drug efflux mediated by ATP-binding cassette (ABC) transporters constitutes the most relevant pathway [7-9]. The human $A B C$ superfamily of genes encompasses 48 functional transporters distributed across seven subfamilies [10]. Importantly, research over the past decade have implicated a multitude of genetic variations in $A B C$ transporter genes in differences in response and toxicity of breast cancer treatment, of which $A B C B 1$ (encoding MDR1 also known as P-gp), $A B C C 1$ (encoding MRP1) and $A B C G 2$ (encoding BCRP) are most extensively studied. While the 


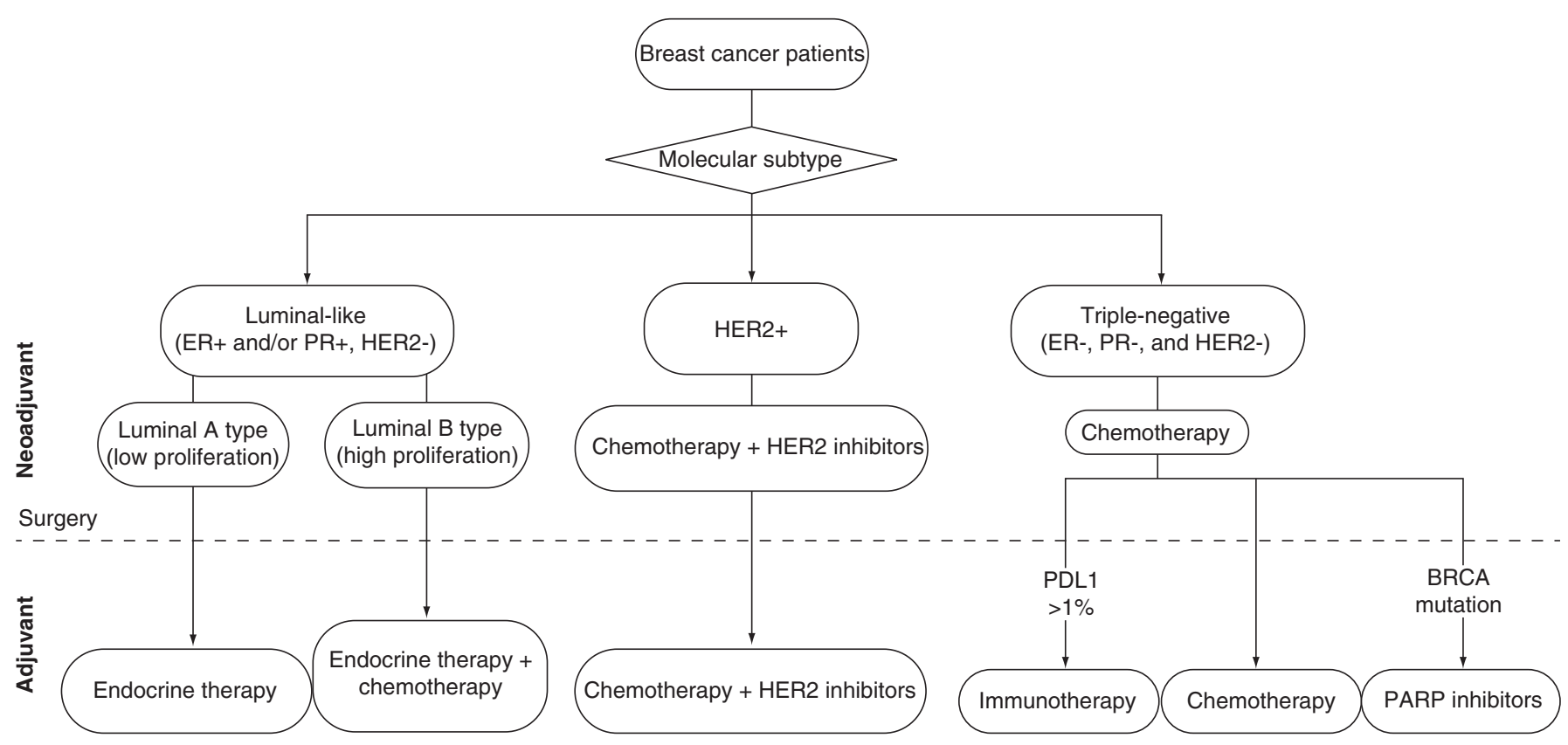

Figure 1. Simplified algorithm for breast cancer treatment stratification. Breast cancer management largely depends on the tumor burden and molecular subtypes. Patients with hormone receptor-positive luminal-like types receive adjuvant endocrine therapy after surgery with or without chemotherapy, depending on the risk of recurrence. HER2 positive cancers are treated with chemotherapy and HER2 inhibitors in both neoadjuvant and adjuvant setting. Triple-negative subtypes receive chemotherapy and in case of a lack of complete response after surgery, treatment with PARP inhibitors or immunotherapy are potential options depending on BRCA status and PDL1 expression, respectively. We want to emphasize that the algorithm presented here is simplified for the sake of clarity and we refer to excellent recent reviews for a more detailed stratification of breast cancer management strategies $[3,6]$.

impact of genetic variants in $A B C$ transporters on cancer therapy has been excellently reviewed previously, these works were published multiple years ago or did not focus on breast cancer [11-15]. In the following, we thus revisit this topic and provide a comprehensive update and critical review of genetic $A B C$ variability as biomarkers for pharmacokinetics, response and toxicity in breast cancer treatment.

\section{$A B C B 1$ (MDR1 or P-gp)}

MDR1 is the most extensively studied $A B C$ transporter and mediates the transport of a wide spectrum of chemotherapeutic drugs including anthracyclines, alkaloids, taxanes, bisantrene and other cytotoxic drug substrates [16,17]. MDR1 is highly expressed in intestine, liver and kidney, as well as in the blood-brain barrier. Transporter localization is highly polarized within the plasma membrane, facilitating the directional extrusion of drugs and other substrates. While a total of 990 variants have been identified in $A B C B 1$ that affect the amino acid sequence of its respective gene product [10], only three exonic and one intronic variant have been implicated in altered toxicity or response to breast cancer therapy (Table 1). The three exonic variants rs2032582, rs1128503 and rs1045642 are localized within a $>40 \mathrm{~kb}$ haplotype block in strong linkage disequilibrium with $\mathrm{D}^{\prime}>0.7$ whereas the intronic variant rs3213619 is not linked [18-20].

Rs2032582 encodes a triallelic missense variation of amino acid position 893 of MDR1. The reference genotype $\mathrm{G}($ global MAF $=55 \%)$ encodes alanine whereas variants $\mathrm{T}(\mathrm{MAF}=41.4 \%)$ and $\mathrm{A}(\mathrm{MAF}=3.6 \%)$ encode serine and threonine, respectively. Evidence regarding the impact of the different variant states on transporter activity is conflicting [43,44]. In the context of breast cancer, six studies have found significant associations between rs 2032582 and toxicity or response. Variant alleles are associated with decreased risk of hematological (leukopenia) and nonhematological (fever, fatigue) adverse events due to docetaxel [21-23] and a reduced risk of paclitaxel resistance [24]. By contrast, rs2032582 variants associated with increased toxicity risk and improved response to anthracyclines [24-26], suggesting substrate-specific differences in variant effects.

The common silent variant rs1045642 (I1145I) has been shown to alter MDR1 function in vitro by introduction of a rare codon that alters cotranslational folding [45]. In breast cancer, the rs 1045642 variant $T$ allele is consistently 
Table 1. $A B C B 1$ variants associated with pharmacokinetics, toxicity or clinical outcomes in breast cancer treatment.

\begin{tabular}{|c|c|c|c|c|c|c|c|}
\hline Variant & RSID & MAF & Drug & $\begin{array}{l}\text { Sample size } \\
\text { (n) }\end{array}$ & Variant effect & Effect size & Ref. \\
\hline \multirow[t]{7}{*}{$\begin{array}{l}\text { c. } 2677 G>T / A \\
(A 893 S / T)\end{array}$} & rs2032582 & $\begin{array}{l}\text { G: } 0.55 \\
\text { T: } 0.414\end{array}$ & DTX, EPI and CPA & 59 & $\begin{array}{l}\text { Decreased risk of fever } \\
\text { and febrile neutropenia }\end{array}$ & $\begin{array}{l}\text { Fever: } \mathrm{OR}=0.15 \text { vs } \mathrm{GG} \\
\text { Febrile neutropenia: }\end{array}$ & [21] \\
\hline & & A: 0.036 & & & & $\mathrm{OR}=0.13$ vs $\mathrm{GG}$ & \\
\hline & & & DTX & 110 & Decreased fatigue & $P=0.03$ vs $G G$ & [22] \\
\hline & & & PTX/DTX after FAC & 132 & $\begin{array}{l}\text { Decreased risk of } \\
\text { leukopenia grade } \geq 2\end{array}$ & $\begin{array}{l}\mathrm{OR}=0.15, \mathrm{TT} \text { vs GG} \\
\mathrm{p}=0.047\end{array}$ & [23] \\
\hline & & & PTX and ANT & 121 & $\begin{array}{l}\text { Lower risk of drug } \\
\text { resistance }\end{array}$ & $\begin{array}{l}\text { PTX: OR }=0.26 \text { vs GG } \\
\text { ANT: OR }=0.67 \text { vs GG }\end{array}$ & [24] \\
\hline & & & DOX and CPA & 141 & $\begin{array}{l}\text { Increased risk of } \\
\text { leukopenia grade } \geq 3\end{array}$ & $\begin{array}{l}\mathrm{OR}=3.8(1.44-9.81) \\
\mathrm{p}=0.007(\mathrm{~A} / \mathrm{T} \text { vs } \mathrm{G})\end{array}$ & [25] \\
\hline & & & ANT & 487 & Increased ANT response & $\begin{array}{l}\text { OR }=1.7(0.79-3.61) \\
p=0.18 \\
\text { vs GG }\end{array}$ & [26] \\
\hline \multirow[t]{7}{*}{ c. $1236 \mathrm{C}>\mathrm{T}(\mathrm{G} 412 \mathrm{G})$} & rs1128503 & 0.545 & DOX & 62 & Increased DOX levels & $\begin{array}{l}36.8 \text { vs } 21.8 \\
C_{\max }^{*} \text { dose }^{-1 *} \text { BSA }^{-1} ; \\
p=0.03 \\
\text { (CT }+ \text { TT vs CC) }\end{array}$ & [27] \\
\hline & & & $\mathrm{FAC} / \mathrm{FEC}$ & 100 & $\begin{array}{l}\text { Increased FAC/FEC } \\
\text { chemotherapy response }\end{array}$ & $\begin{array}{l}\mathrm{OR}=5.2(1.3-20.2) \\
\mathrm{p}=0.02(\mathrm{CT} \text { vs } \mathrm{CC})\end{array}$ & [28] \\
\hline & & & FAC/FEC & 207 & $\begin{array}{l}\text { Increased grade } 2-4 \\
\text { toxicity }\end{array}$ & $\begin{array}{l}\text { OR }=1.9(1.06-3.39) \\
p=0.03(T T \text { vs } C T+C C)\end{array}$ & [28] \\
\hline & & & $\mathrm{FAC} / \mathrm{FEC}$ & 207 & $\begin{array}{l}\text { Increased dose delay or } \\
\text { reduction due to } \\
\text { neutropenia }\end{array}$ & $\begin{array}{l}\mathrm{OR}=2.5(1.15-5.55) \\
\mathrm{p}=0.02(\mathrm{TT} \text { vs } \mathrm{CT}+\mathrm{CC})\end{array}$ & [28] \\
\hline & & & DTX & 129 & Increased response & $\begin{array}{l}\mathrm{OR}=2.9(1.15-7.5) \\
\mathrm{p}=0.03(\mathrm{TT}+\mathrm{CT} \text { vs CC })\end{array}$ & [29] \\
\hline & & & DTX & 150 & $\begin{array}{l}\text { Increased peripheral } \\
\text { neuropathy }\end{array}$ & $\begin{array}{l}\mathrm{OR}=1.3(0.63-2.74)(\mathrm{CT} \text { vs } \\
\mathrm{CC})\end{array}$ & [30] \\
\hline & & & PTX & 127 & $\begin{array}{l}\text { Increased peripheral } \\
\text { neuropathy grade } \geq 2\end{array}$ & $\begin{array}{l}\mathrm{OR}=2.4(1.07-5.4) \\
\mathrm{p}=0.03(\mathrm{TT} \text { vs } \mathrm{CC}+\mathrm{CT})\end{array}$ & [31] \\
\hline \multirow[t]{11}{*}{ c. $3435 C>T(11145 \mathrm{I})$} & rs1045642 & 0.511 & DOX, CPA and DTX & 101 & Increased response & $\begin{array}{l}\mathrm{OR}=4.6(1.3-16.1) \\
\mathrm{p}=0.02(\mathrm{TT} \text { vs } \mathrm{CC}+\mathrm{CT})\end{array}$ & [32] \\
\hline & & & $\begin{array}{l}\text { DOX, CPA, DTX and } \\
\text { trastuzumab }\end{array}$ & 86 & $\begin{array}{l}\text { Increased plasma } \\
\text { concentration }\end{array}$ & $\begin{array}{l}\text { AUC } 5075 \text { vs } \\
2727 \mathrm{mg}^{*} \mathrm{~h}^{-1} * \mathrm{l}^{-1},(\mathrm{CT}+\mathrm{TT} \\
\text { vs CC) }\end{array}$ & [33] \\
\hline & & & ANT & 221 & $\begin{array}{l}\text { Shorter time to } \\
\text { progression }\end{array}$ & $\begin{array}{l}\text { PFS } 43.25 \text { vs } 121.8 \text { months, } \\
p=0.049 \\
\text { (CT }+ \text { TT vs CC) }\end{array}$ & [34] \\
\hline & & & ANT & 153 & Worse clinical response & $\begin{array}{l}\text { Response rate } 33.3 \% \text { vs } \\
71.2 \% ; p=0.001 \text { (TT vs } \\
C T+C C)\end{array}$ & [35] \\
\hline & & & ANT & 1173 & $\begin{array}{l}\text { Increased therapeutic } \\
\text { response }\end{array}$ & $\begin{array}{l}\mathrm{OR}=2.7(1.2-6.2) ; \mathrm{p}=0.02 \\
(\mathrm{CT}+\mathrm{TT} \text { vs } \mathrm{CC})\end{array}$ & [26] \\
\hline & & & ANT & 135 & Increased OS and PFS & $\begin{array}{l}\text { OS } 70.6 \text { vs } 49.5 \text { months; } \\
p=0.02 \text { (CT }+T \text { Ts } C C) \\
\text { PFS } 81.2 \text { vs } 52.3 \text { months; } \\
p=0.001 \text { (CT }+T \text { vs } C C)\end{array}$ & [26] \\
\hline & & & $\begin{array}{l}\text { Adriamycin, CPA and } \\
\text { DTX }\end{array}$ & 218 & $\begin{array}{l}\text { Increased risk of } \\
\text { neutropenia }\end{array}$ & $P=0.015$ (TT vs CC) & [36] \\
\hline & & & CPA, MTX, FU and TAM & 30 & Higher risk of recurrence & $\begin{array}{l}\mathrm{HR}=5.1(1.05-24.7) \\
\mathrm{p}=0.043(\mathrm{CT} \text { vs CC })\end{array}$ & [37] \\
\hline & & & Adjuvant taxane & 219 & $\begin{array}{l}\text { Increased risk of } \\
\text { neurotoxicity grade } \geq 2\end{array}$ & $\begin{array}{l}\mathrm{OR}=2.8(1.17-6.5) \\
\mathrm{p}=0.017(\mathrm{TT} \text { vs } \mathrm{CC}+\mathrm{CT})\end{array}$ & [38] \\
\hline & & & DTX and doxorubicin & 216 & Increased OS & $P=0.024(T T$ vs $C C+C T)$ & [39] \\
\hline & & & DTX & 110 & Increased risk of rash & $\mathrm{P}<0.05$ (CT vs $\mathrm{CC}$ ) & [22] \\
\hline
\end{tabular}

Values in square brackets indicate $95 \% \mathrm{Cl}$.

ANT: Anthracyclines; AUC: Area under the curve; BSA: Body surface area; CPA: cyclophosphamide; DOX: Doxorubicin; DTX: Docetaxel; EPI: Epirubicin; FAC: 5-Fluorouracil, anthracycline, cyclophosphamide regimen; FEC: 5-Fuorouracil, epirubicin, cyclophosphamide regimen; FU: 5-Fluorouracil; MAF: Minor allele frequency; MTX: Methotrexate; OS: Overall survival; PFS: Progression-free survival; PTX: Paclitaxel; TAM: Tamoxifen. 
Table 1. $A B C B 1$ variants associated with pharmacokinetics, toxicity or clinical outcomes in breast cancer treatment (cont.).

\begin{tabular}{|c|c|c|c|c|c|c|c|}
\hline \multirow[t]{4}{*}{ Variant } & RSID & MAF & Drug & $\begin{array}{l}\text { Sample size } \\
\text { (n) }\end{array}$ & Variant effect & Effect size & Ref. \\
\hline & & & PTX & 121 & Increased OS & $\begin{array}{l}\mathrm{HR}=3.5(1.16-3.51) \\
\mathrm{p}=0.026(\mathrm{CT} \text { vs } C \mathrm{C})\end{array}$ & [24] \\
\hline & & & TAM & 71 & $\begin{array}{l}\text { Longer time to } \\
\text { progression }\end{array}$ & $P=0.012$ & [40] \\
\hline & & & Anastrozole & 110 & Reduced risk of arthralgia & $\begin{array}{l}\text { OR }=0.3(0.11-0.89) \\
p=0.029(T T \text { vs } C C+C T)\end{array}$ & [41] \\
\hline c. $134-52 \mathrm{~T}>\mathrm{C}$ (intronic) & rs3213619 & 0.053 & PTX & 1303 & $\begin{array}{l}\text { Reduced sensory } \\
\text { neuropathy }\end{array}$ & $\begin{array}{l}\mathrm{OR}=0.47(0.28-0.79) \\
\mathrm{p}=0.004(\mathrm{C} \text { vs T })\end{array}$ & [42] \\
\hline
\end{tabular}

Values in square brackets indicate $95 \% \mathrm{Cl}$.

ANT: Anthracyclines; AUC: Area under the curve; BSA: Body surface area; CPA: cyclophosphamide; DOX: Doxorubicin; DTX: Docetaxel; EPI: Epirubicin; FAC: 5-Fluorouracil, anthracycline, cyclophosphamide regimen; FEC: 5-Fuorouracil, epirubicin, cyclophosphamide regimen; FU: 5-Fluorouracil; MAF: Minor allele frequency; MTX: Methotrexate; OS: Overall survival; PFS: Progression-free survival; PTX: Paclitaxel; TAM: Tamoxifen.

Table 2. Variants in $A B C C 1$ and $A B C C 2$ associated with pharmacokinetics, toxicity or clinical outcomes in breast cancer treatment.

\begin{tabular}{|c|c|c|c|c|c|c|c|c|}
\hline Gene & Variant & RSID & MAF & Drug & $\begin{array}{l}\text { Sample size } \\
\text { (n) }\end{array}$ & Variant effect & Effect size & Ref. \\
\hline \multirow[t]{3}{*}{$A B C C 1$} & c.2012G >T (G671V) & rs45511401 & 0.04 & $\mathrm{FEC}+/-\mathrm{DOX}$ & 1012 & $\begin{array}{l}\text { Increased risk of febrile } \\
\text { neutropenia }\end{array}$ & $\begin{array}{l}\text { OR }=17.6(2.2-35.8)(\mathrm{TT} \\
\text { vs GG) }\end{array}$ & [46] \\
\hline & $c .825 T>C(V 275 V)$ & rs246221 & 0.34 & $\mathrm{FEC}+/-\mathrm{DOX}$ & 994 & $\begin{array}{l}\text { Increased risk of febrile } \\
\text { neutropenia }\end{array}$ & $\mathrm{OR}=2.0(\mathrm{CC}$ vs TT $)$ & [47] \\
\hline & $\begin{array}{l}\text { c. } 1988+219 \mathrm{G}>\mathrm{T} \\
\text { (Intronic) }\end{array}$ & rs4148350 & 0.07 & $\mathrm{FEC}+/-\mathrm{DOX}$ & 1012 & $\begin{array}{l}\text { Increased risk of febrile } \\
\text { neutropenia }\end{array}$ & $\begin{array}{l}\mathrm{OR}=21.1 \\
(3.1-416.6)(T T \text { vs GG) }\end{array}$ & [46] \\
\hline \multirow[t]{2}{*}{$A B C C 2$} & $\begin{array}{l}\text { c. } 4146+154 \mathrm{~A}>\mathrm{G} \\
\text { (intronic) }\end{array}$ & rs3740065 & 0.14 & TAM & 282 & $\begin{array}{l}\text { Reduced } \\
\text { recurrence-free survival }\end{array}$ & $\begin{array}{l}\mathrm{HR}=10.64(1.4-79) \\
\mathrm{p}=0.0002(\mathrm{GG} \text { vs } A A)\end{array}$ & [51] \\
\hline & c. $4544 \mathrm{G}>\mathrm{A}(\mathrm{C} 1515 \mathrm{Y})$ & rs8187710 & 0.06 & PTX & 1303 & $\begin{array}{l}\text { Increased } \\
\text { taxane-related sensory } \\
\text { neuropathy }\end{array}$ & $\begin{array}{l}\mathrm{OR}=0.63(0.42-0.93) \\
\mathrm{p}=0.02(\mathrm{~A} \text { vs } \mathrm{G})\end{array}$ & [42] \\
\hline
\end{tabular}

associated with increased toxicity [22,36,38] and improved outcomes [24,39] for patients treated with taxanes. In contrast, the findings for anthracyclines are conflicting and remain inconclusive with reports of increased [26,32] and decreased response and outcomes [34,35] of the variant allele. Similar to rs2032582, effects of rs1045642 on pharmacokinetics and response to MDR1 substrates beyond breast cancer are inconsistent [43,44].

In vitro evidence for the synonymous variant rs1128503 (G412G) suggests that it is functionally neutral by itself [45]. Surprisingly, the available association data in breast cancer unequivocally indicate rs1128503 to be significantly linked with increased exposure $\left(\mathrm{c}_{\max }\right)$ to anthracyclines [27], as well as with increased response and toxicity to anthracyclines [28] and taxanes [29-31]. Given that rs2032582, rs1128503 and rs1045642 are almost completely linked and associations were analyzed by variant and rarely by haplotype, the available data does not allow to precisely assign the observed effects to an individual variant. We conclude based on the available evidence that the three exonic variants rs2032582, rs1 128503 and rs1045642 consistently associate with increased exposure, toxicity and efficacy of taxanes, whereas data for anthracyclines is conflicting.

\section{ABCC1 (MRP1)}

One missense (G671V), one synonymous (V275V) and one intronic variant have been suggested as biomarkers for breast cancer therapy outcomes or toxicity (Table 2). Presence of G671V (rs45511401) correlated with febrile neutropenia in patients treated with fluorouracil, epirubicin and cyclophosphamide (FEC) with odds ratios (ORs) of 1.7-1.8 and 16.4-17.6 for heterozygous and homozygous variant carriers [46,47]. Rs45511401 is ethogeographically highly variable with highest frequencies in Europeans (5.6\%) and lowest frequencies in East Asians $(<0.1 \%)[10]$. However, despite the setting of the study being in Europe (Belgium), only 4 homozygous carriers were identified albeit the relatively high study sample size $(n=1012)$. While this association is corroborated by findings from a 
study in non-Hodgkin lymphoma patients that also found increased risk of anthracycline toxicity in variant carriers compared with controls [48], other studies [49,50] did not observe significant effects. Febrile neutropenia risk for breast cancer patients receiving FEC was furthermore reported to be significantly associated with the synonymous variant $\mathrm{V} 275 \mathrm{~V}$ (rs246221) as well as the intronic variant rs4148350 with ORs of 1.7-2 and 21.1-22.1, respectively [46,47]. In contrast to $A B C B 1$, the three variations in $A B C C 1$ were only weakly linked $\left(\mathrm{R}^{2}<0.2\right)$. Notably, the two studies describing effects of $A B C C 1$ variations on febrile neutropenia risk [46,47] have been reported by the same group using the same cohort of 1,012 Belgian breast cancer patients (apart from the exclusion of 18 patients receiving chemotherapy prior to FEC in one of the studies) and thus results cannot be seen as independently confirmatory.

We recently analyzed the association of germline variability in $\mathrm{ABC}$ transporters with disease-specific survival (DSS) in various cohorts from The Cancer Genome Atlas Program [52]. The results indicated that variant burden in $A B C C 1$, but not previously reported $A B C$ candidate variants, was a strong predictor of DSS specifically in those breast cancer patients who received the MRP1 substrates cyclophosphamide $(\mathrm{p}=0.001)$ and doxorubicin $(\mathrm{p}=0.009)$ but not in hormone receptor-positive patients on endocrine therapy $(\mathrm{p}=0.13)$. By contrast $A B C C 1$ variability was not significantly associated with DSS in clear cell renal carcinoma or hepatocellular carcinoma patients where treatment is not based on MRP1 substrates. These findings support a model in which multiple, often rare variations with individually small effect sizes modulate clinical outcomes in breast cancer patients undergoing chemotherapy.

\section{$A B C C 2$ (MRP2)}

Only two SNPs in $A B C C 2$ have been linked to breast cancer treatment outcomes (Table 2). A study of 1303 early breast cancer patients identified a protective effect of the missense variant rs8187710 (C1515Y) with paclitaxelinduced sensory neuropathy [42]. Paclitaxel is a MRP2 substrate [53] and plausibility of this finding is further supported by result from recombinant in vitro systems that show that the variant results in impaired transporter function [54,55].

An intronic variant in $A B C C 2$ (rs3740065) has furthermore been linked to reduced recurrence-free survival in hormone receptor-positive breast cancer patients on tamoxifen monotherapy with an OR of 10.6 for homozygous variant carriers [51]. However, in contrast to CYP2D6 genotypes, this variant did not result in alterations of tamoxifen pharmacokinetics. Notably, there is no clear evidence that tamoxifen is a substrate of MRP2 and, to the best of our knowledge, this association has not been replicated in independent studies despite its high MAF of $14 \%$ and the alleged high effect size, thus casting considerable doubt on the utility of rs3740065 as a biomarker for tamoxifen treatment outcomes.

\section{$A B C G 2$ (BCRP)}

$A B C G 2$ encodes the breast cancer resistance protein (BCRP) that received its name for being originally identified in a breast cancer cell line. Surprisingly however, despite its name, studies that implicate BCRP variability in breast cancer therapy resistance are largely lacking and we only identified a single study that reported an association between $A B C G 2$ variants and response or therapeutic outcomes in breast cancer patients [56]. In this study, the authors found an association between Q141K (rs2231142) and improved response, as well as a link between V12M (rs2231137) and increased overall survival in hormone receptor-positive breast cancer patients after postoperative anthracycline-based chemotherapy with hazard ratios (HRs) between 0.5 and 0.7 (Table 3). Experimental evidence suggests that V12M is functionally neutral, whereas Q141K results in reduced expression levels [57-60]. Furthermore, Q141 K but not V12M have been consistently implicated in differences in the pharmacokinetics of BCRP substrates, such as statins, camptothecins and mitoxantrone [61,62]. However, whereas BCRP provides resistance to a variety of chemotherapeutic agents in vitro, BCRP expression does not predict response to chemotherapy, relapse or progression-free survival in vivo [63-65]. Substantial in vitro evidence moreover suggests that acquired $A B C G 2$ mutations can increase chemotherapy resistance [66,67]. Again, in vivo evidence confirming these findings have to our knowledge not been reported.

\section{Associations with variants in other $A B C$ genes}

Only few reports have associated variants in other $A B C$ transporter genes with response or toxicity in breast cancer (Table 3). One report associated $A B C C 4$ genotypes with toxicity in breast cancer patients receiving cyclophosphamide-containing regimens [68]. The authors report that the intronic variant rs9561778 (MAF $=18 \%)$ was associated with both gastrointestinal toxicity $(\mathrm{p}=0.0002)$ and leukopenia $(\mathrm{p}=0.014)$ in both, an exploratory $(\mathrm{n}=216)$ and an independent replication cohort $(\mathrm{n}=187)$. Available evidence suggests that cyclophosphamide 
Table 3. Variants in other $A B C$ genes associated with pharmacokinetics, toxicity or clinical outcomes in breast cancer treatment.

\begin{tabular}{|c|c|c|c|c|c|c|c|c|}
\hline Gene & Variant & RSID & MAF & Drug & $\begin{array}{l}\text { Sample size } \\
\text { (n) }\end{array}$ & Variant effect & Effect size & Ref. \\
\hline$A B C C 4$ & $\begin{array}{l}\text { c. } 3366+1243 C>T \\
\text { (Intronic) }\end{array}$ & rs9561778 & 0.18 & CPA & 403 & $\begin{array}{l}\text { Increased risk of } \\
\text { leukopenia grade } \geq 3 \\
\text { or gastrointestinal } \\
\text { toxicity grade } \geq 2\end{array}$ & $\begin{array}{l}\mathrm{OR}=2.06(1.36-3.1) \\
\mathrm{p}=0.04(\mathrm{~T} \text { vs } \mathrm{C})\end{array}$ & [68] \\
\hline$A B C C 5$ & $\begin{array}{l}\text { g. }+7161 \mathrm{~T}>C \\
\text { (intergenic) }\end{array}$ & rs1533682 & 0.38 & $\mathrm{DOX}+\mathrm{CPA}$ & 62 & $\begin{array}{l}\text { Increased DOX } \\
\text { clearance }\end{array}$ & $\mathrm{P}=0.04(\mathrm{CC}$ vs TT $)$ & [69] \\
\hline$A B C C 6$ & c.3803G >A (R1268Q) & rs2238472 & 0.25 & $\begin{array}{l}\text { DOX }+/- \\
\text { trastuzumab }\end{array}$ & 100 & $\begin{array}{l}\text { Decreased risk of } \\
\text { febrile neutropenia }\end{array}$ & $P=0.012(A$ vs $G)$ & [70] \\
\hline$A B C G 1$ & $\begin{array}{l}\text { c. } 973+672 G>A \\
\text { (intronic) }\end{array}$ & rs3788007 & 0.18 & $\begin{array}{l}\mathrm{DOX}+/- \\
\text { trastuzumab }\end{array}$ & 100 & $\begin{array}{l}\text { Increased risk of febrile } \\
\text { neutropenia }\end{array}$ & $P=0.0045(A$ vs $G)$ & [70] \\
\hline \multirow[t]{4}{*}{$A B C G 2$} & c. $421 \mathrm{C}>\mathrm{A}(\mathrm{Q} 141 \mathrm{~K})$ & rs2231142 & 0.12 & Preoperative ANT & 1169 & Increased response & $\begin{array}{l}\mathrm{OR}=4.7(0.83-26.4) \\
\mathrm{p}=0.04(\mathrm{AA} \text { vs } C \mathrm{C})\end{array}$ & [56] \\
\hline & c.34G $>$ A $(\mathrm{V} 12 \mathrm{M})$ & rs2231137 & 0.11 & ANT & $\begin{array}{l}421 \text { postop- } \\
\text { erative } \\
\text { therapy }\end{array}$ & Increased OS & $\begin{array}{l}\mathrm{HR}=0.7 ; \mathrm{p}=0.044(\mathrm{AA} \\
\text { vs } \mathrm{GG})\end{array}$ & [56] \\
\hline & & & & ANT & $240 \mathrm{ER}+$ & Increased OS & $\begin{array}{l}H R=0.50 ; p=0.023 \\
(A A \text { vs } G G)\end{array}$ & [56] \\
\hline & & & & ANT & $218 \mathrm{PR}+$ & Increased OS & $\begin{array}{l}H R=0.56 ; p=0.042 \\
(A A \text { vs } G G)\end{array}$ & [56] \\
\hline
\end{tabular}

Values in square brackets indicate $95 \% \mathrm{Cl}$.

ANT: Anthracyclines; CPA : Cyclophosphamide; DOX: Doxorubicin; ER: Estrogen receptor; MAF: Minor allele frequency; OS: Overall survival; PR: Progesterone receptor.

is an MRP4 substrate in vitro [71] and in vivo [72]. However, whether rs9561778 itself has functional effects or is linked to other variants that impact MRP4 function has not been addressed so far.

In addition, in a small study of 62 Asian breast cancer patients the intergenic variant rs 1533682 localized $2 \mathrm{~kb}$ downstream of $A B C C 5$ was reported to associate with increased doxorubicin clearance [69]. However, given the lack of further genetic or experimental validations, care is warranted when interpreting this finding. Similarly, Awada and colleagues reported associations for rs2238472 (R1268Q) in ABCC6 and rs3788007 in ABCG1 without accounting for multiple testing, strongly suggesting the findings to be statistical artifacts [70].

\section{Conclusion}

Robust in vitro evidence demonstrates important roles of $\mathrm{ABC}$ transporters in chemotherapy resistance in breast cancer cell lines and suggests that both germline and acquired variations can be significant modulators of drug sensitivity. Incentivized by these findings, a multitude of studies have set out to investigate associations between $A B C$ variants and various clinical end points, including drug response, toxicity, relapse and survival, with the goal to identify biomarkers that could guide the fine-tuning of therapeutic regimens and assist in prognostic modeling. Here, we systematically reviewed the literature reporting associations between genetic $A B C$ transporter variability and treatment outcomes in breast cancer patients and provide a critical synthesis of the available data.

The vast majority of $A B C$ associations with treatment outcomes in breast cancer were described for patients undergoing chemotherapy using regimes based on anthracyclines, taxanes and cyclophosphamide and, inversely, the majority of SNPs associated with anthracycline pharmacogenomics were identified in drug transporters [73]. In contrast, no studies have associated $A B C$ variants in breast cancer patients with outcomes or toxicity of platinumbased agents, HER2 or PARP inhibitors. Furthermore, only three studies identified $A B C$ biomarkers (I1145I in $A B C B 1$ and the intronic SNP rs3740065 in $A B C C 2)$ for endocrine therapy using tamoxifen or anastrozole. MDR1 transports the tamoxifen metabolites endoxifen and 4-hydroxytamoxifen [74,75], whereas neither the parent nor its metabolites have been shown to be substrates of MRP2. Based on these findings we conclude that the role of $A B C$ transporter polymorphisms for endocrine therapy is limited to few variants in $A B C B 1$ and there is currently no evidence that $A B C$ transporter genotype affects treatment with HER2 or PARP inhibitors.

Changes in transporter activity can be expected to result in alterations of pharmacokinetics and/or in changes of intracellular concentrations. A multitude of studies have evaluated relations between $A B C B 1$ variants and drug pharmacokinetics. In the context of breast cancer, only two associations with pharmacokinetic changes have been presented in which rs1045642 (I1145I) increases the area under the plasma concentration-time curve of docetaxel [33] 


\begin{tabular}{|c|c|c|c|c|c|c|c|}
\hline Gene & RSID & Variant & Efficacy & Toxicity & $\begin{array}{l}\text { Experimental } \\
\text { evidence }\end{array}$ & Genetic & Ref. \\
\hline \multirow[t]{4}{*}{$A B C B 1$} & rs2032582 & A893S/T & Increased & Conflicting & Conflicting & Decreased IBD risk & [45,86-88] \\
\hline & rs1128503 & G412G & Increased & Increased & & Benign & \\
\hline & rs1045642 & $|1145|$ & Conflicting & Conflicting & & Benign & \\
\hline & rs3213619 & Intronic & NA & Decreased & NA & NA & \\
\hline \multirow[t]{3}{*}{$A B C C 1$} & rs45511401 & G671V & NA & Increased & Conflicting & $\begin{array}{l}\text { Gene not } \\
\text { disease-associated }\end{array}$ & {$[89,90]$} \\
\hline & rs246221 & V275V & NA & Increased & NA & & \\
\hline & rs4148350 & Intronic & NA & Increased & NA & & \\
\hline \multirow[t]{2}{*}{$A B C C 2$} & rs3740065 & Intronic & Decreased & NA & NA & NA & \\
\hline & rs8187710 & C1515Y & NA & Increased & Reduced function & Benign & {$[54,55]$} \\
\hline$A B C C 4$ & rs9561778 & Intronic & NA & Increased & NA & $\begin{array}{l}\text { Gene not } \\
\text { disease-associated }\end{array}$ & \\
\hline$A B C C 6$ & rs2238472 & R1268Q & NA & Decreased & NA & Benign & \\
\hline$A B C G 1$ & rs3788007 & Intronic & NA & Increased & NA & $\begin{array}{l}\text { Gene not } \\
\text { disease-associated }\end{array}$ & \\
\hline \multirow[t]{2}{*}{$A B C G 2$} & rs2231142 & Q141K & Increased & NA & Reduced function & $\begin{array}{l}\text { Increased risk of } \\
\text { hyperuricemia }\end{array}$ & {$[58,59]$} \\
\hline & rs2231137 & V12M & Increased & NA & $\begin{array}{l}\text { Functionally } \\
\text { neutral }\end{array}$ & $\begin{array}{l}\text { Decreased risk of } \\
\text { hyperuricemia }\end{array}$ & {$[59,60]$} \\
\hline
\end{tabular}

Disease associations were extracted from ClinVar.

NA: Not available.

and rs1128503 (G412G) increased doxorubicin exposure [27]. Furthermore, no conclusive associations have been identified with other well characterized MDR1 substrates, including cyclosporine [76], various anti-epileptics [77], fexofenadine [78] and digoxin [79]. Similarly, lack of correlation or conflicting results were reported for associations between $A B C G 2$ genotypes and the tyrosine kinase inhibitor BCRP substrates erlotinib, gefitinib and imatinib [8082]. These results suggest that the impact of individual $A B C$ transporter variants on drug pharmacokinetics is very limited. In contrast, there is more evidence for pharmacogenetic effects on intracellular drug concentrations, as evidenced by genotype-dependent differences in drug efficacy or toxicity.

$\mathrm{ABC}$ transporters furthermore have important physiological roles and mutations in multiple genes that encode pharmacologically relevant transporters can also cause genetic disease, including $A B C C 2$ with Dubin-Johnson syndrome (OMIM 237500), ABCC6 with pseudoxanthoma elasticum (OMIM 264800) and ABCG2 with gout (OMIM 138900). Notably, only few of those variants that associate with drug pharmacokinetics, response or toxicity also associate with congenital disease. The most notable example is rs2231142(Q141K) in $A B C G 2$, which correlates with increased ( $\mathrm{HR}=1.74 ; \mathrm{p}=3 \times 10^{-60}$ in Caucasians; $\mathrm{HR}=2.1 ; \mathrm{p}=10^{-11}$ in Asians) risk of hyperuricemia, thus aligning with the experimentally determined reduction in activity of this transporter variant $[83,84]$. In addition, rs2231137 $(\mathrm{V} 12 \mathrm{M})$ was found to be mildly protective for hyperuricemia $(\mathrm{HR}=0.67$; $\mathrm{p}=0.005$ ) [84]. Besides those $A B C G 2$ variants, the $\mathrm{G}$ allele of rs2032582 (A893) in $A B C B 1$ was found to associate with IBD by both case-control analysis $(\mathrm{p}=0.002)$ and pedigree disequilibrium tests $(\mathrm{p}=0.0002)$, providing genetic support for the relatively reduced function of the A893 variant [85]. In the simplest model, it could be expected that reduced transporter activity might result in increased intracecllular drug levels, resulting in increased efficacy but also increased risk of toxicity and possibly an association with genetic disease in case of a transporter with physiologically essential functions. However, with the exception of $A B C G 2 \mathrm{rs} 2231142$ (Q141K), results are not consistent across experimental, pharmacological and genetic levels of evidence (Table 4).

Importantly, the published studies are highly heterogeneous in quality with regards to sample size, cohort selection and statistical stringency. The majority of studies recruited patients with different breast cancer subtypes, irrespective of hormone receptor and HER2 status, which complicates result interpretation particularly for those studies that considered response as their primary end point. Furthermore, patients were recruited across tumor 
stages and grades and these parameters were rarely considered as confounding variables despite their importance for patient outcomes, which hampers the possibility to conduct meaningful meta-analyses. Moreover, most identified biomarkers were only identified in a single study, lacked replication and should thus be interpreted very cautiously. Notable exceptions are variants rs2032582 (A893T/S), rs1 128503 (G412G) and rs1045642 (I1145I) in ABCB1 that have been repeatedly implicated in response and toxicity to astracyclines and taxanes, albeit sometimes with opposite effects. We see two possible explanations for the lack of replication: the reported result is false-positive or the association is highly sensitive to one or more unidentified factors, such as the molecular or histological signature of the cancer, disease stage, the exact choice of treatment regimen (choice of drugs, doses, timings), demographic or other factors unique for the analyzed cohort, thereby obstructing replication of the finding in question. This lack of replication is particularly concerning for variations with no or little functional or mechanistic support, such as synonymous or intronic variants or missense variants that do not affect transporter function, which combined comprise the majority of identified associations. Of note, while generally assumed to be functionally neutral, such variants can impact transporter function, as evidenced by the synonymous variants G412G and I1145I in $A B C B 1$ that disrupt the cotranslational folding process via the introduction of rare codons thereby reducing transporter activity [45].

Overall, we conclude that individual $A B C$ transporter variants cannot serve as clinically actionable biomarkers for breast cancer therapy. The most promising associations are rs2032582, rs1128503 and rs 1045642 in $A B C B 1$ for the prediction of toxicity and response to taxanes, for which the literature appears consistent. However, the relatively small effect sizes also do not warrant implementation of those variants into clinical decision-support. In contrast, the same variants are poor predictors for clinically relevant end points of anthracycline or endocrine therapy. Variants in other ABC transporters lack replication and mechanistic support and are thus at present do not constitute clinically useful biomarkers.

\section{Future perspective}

Notably, the vast majority of studies were based on the interrogation of selected candidate variants with mostly high variant frequencies by arrays or targeted PCRs. However, analyses of genomic data from $>130,000$ individuals revealed that $A B C$ transporters harbor more than 62,000 exonic variants as well as many more intronic variations, the vast majority of which $(98.5 \%)$ are rare with MAFs $<1 \%$ [10]. This genetic complexity is comparable to other highly polymorphic gene families, such as those encoding CYP enzymes [91,92], SLC [93] or SLCO transporters [94,95]. Analysis of $A B C$ variability in breast cancer patients based on next-generation sequencing (NGS) data revealed a multitude of variants with complex haplotype structures and individually small effect sizes whose incorporation drastically improved the predictive power of outcome models [52]. These findings demonstrate the importance of previously neglected rare genetic variants and advocate for a paradigm shift away from the interrogation of few selected SNPs and toward decision-making based on comprehensive sequencing data in the near future $[96,97]$.

\section{Executive summary}

- Effects of $A B C$ transporter polymorphism on chemotherapy pharmacokinetics, response or toxicity in breast cancer patients is restricted to anthracyclines, taxanes and cyclophosphamide, whereas their relevance for endocrine therapy or HER2/PARP inhibitors are limited.

- Most identified associations lack replication and mechanistic support. This can at least in part be explained by the heterogeneity of the published literature with regards to sample sizes, cohort selection and statistical stringency.

- The only consistent results were obtained for rs2032582, rs1128503 and rs1045642 in $A B C B 1$ for the prediction of toxicity and response to taxanes.

- Recent research indicated that a large number of variations with individually small effect sizes in $A B C C 1$ (MRP1) can better explain treatment outcomes in breast cancer patients treated with MRP1 substrates, whereas no association was found with commonly analyzed candidate single nucleotide polymorphisms. These results suggest that variant effects might be combinatorial and advocate for a shift in strategy away from the interrogation of target single nucleotide polymorphisms toward comprehensive and integrative analyses of mutational burden.

\footnotetext{
Acknowledgments

This work was supported by the Swedish Research Council (grant agreement nos. 2016-01153, 2016-01154 and 2019-01837), by the European Union's Horizon 2020 research and innovation program U-PGx (grant agreement no. 668353) and by the Strategic Research Programmes in Diabetes (SFO Diabetes) and Stem Cells and Regenerative Medicine (SFO StratRegen). X.Q. received support from the China Scholarship Council (grant no. 201600160066).
} 
Financial \& competing interests disclosure

VM Lauschke is shareholder of HepaPredict AB. However, this affiliation does not constitute a conflict of interest as specified by the ICMJE Uniform Requirements. The authors have no other relevant affiliations or financial involvement with any organization or entity with a financial interest in or financial conflict with the subject matter or materials discussed in the manuscript apart from those disclosed.

No writing assistance was utilized in the production of this manuscript.

\section{Open access}

This work is licensed under the Attribution-NonCommercial-NoDerivatives 4.0 Unported License. To view a copy of this license, visit http://creativecommons.org/licenses/by-nc-nd/4.0/

\section{References}

1. Bray F, Ferlay J, Soerjomataram I, Siegel RL, Torre LA, Jemal A. Global cancer statistics 2018: GLOBOCAN estimates of incidence and mortality worldwide for 36 cancers in 185 countries. CA Cancer J. Clin. 68(6), 394-424 (2018).

2. Desantis CE, Ma J, Gaudet MM et al. Breast cancer statistics, 2019. CA Cancer J. Clin. 69(6), 438-451 (2019).

3. Harbeck N, Penault-Llorca F, Cortés J et al. Breast cancer. Nat. Rev. Dis. Primers 5(1), 66 (2019).

4. Robson M, Im S-A, Senkus E et al. Olaparib for metastatic breast cancer in patients with a germline BRCA mutation. New Engl. J. Med. 377(6), 523-533 (2017).

5. Litton JK, Rugo HS, Ettl J et al. Talazoparib in patients with advanced breast cancer and a germline BRCA mutation. New Engl. J. Med. 379(8), 753-763 (2018).

6. Harbeck N, Gnant M. Breast cancer. Lancet 389(10074), 1134-1150 (2017).

7. Wind NS, Holen I. Multidrug resistance in breast cancer: from in vitro models to clinical studies. Int. J. Breast Cancer 2011, 967419 (2011).

8. Robey RW, Pluchino KM, Hall MD, Fojo AT, Bates SE, Gottesman MM. Revisiting the role of ABC transporters in multidrug-resistant cancer. Nat. Rev. Cancer 18(7), 452-464 (2018).

9. Ji X, Lu Y, Tian H, Meng X, Wei M, Cho WC. Chemoresistance mechanisms of breast cancer and their countermeasures. Biomed. Pharmacother. 114, 108800 (2019).

10. Xiao Q, Zhou Y, Lauschke VM. Ethnogeographic and inter-individual variability of human ABC transporters. Hum. Genet. 139(5), 623-646 (2020).

11. Sparreboom A, Danesi R, Ando Y, Chan J, Figg WD. Pharmacogenomics of ABC transporters and its role in cancer chemotherapy. Drug Resist. Updates 6(2), 71-84 (2003).

12. Lockhart AC, Tirona RG, Kim RB. Pharmacogenetics of ATP-binding cassette transporters in cancer and chemotherapy. Mol. Cancer Ther. 2(7), 685-698 (2003).

13. Ishikawa $\mathrm{T}$. Recent advances in pharmacogenomics of $\mathrm{ABC}$ transporters involved in breast cancer therapy. Pharmacogenomics 13(6), 633-636 (2012).

14. Bruhn O, Cascorbi I. Polymorphisms of the drug transporters $A B C B 1, A B C G 2, A B C C 2$ and $A B C C 3$ and their impact on drug bioavailability and clinical relevance. Expert Opin. Drug Metabol. Toxicol. 10(10), 1337-1354 (2014).

15. Hlaváč V, Holý P, Souček P. Pharmacogenomics to predict tumor therapy response: a focus on ATP-binding cassette transporters and cytochromes P450. Journal of Personalized Medicine 10(3), (2020).

16. Ambudkar SV, Kimchi-Sarfaty C, Sauna ZE, Gottesman MM. P-glycoprotein: from genomics to mechanism. Oncogene 22(47), 7468-7485 (2003).

17. Hodges LM, Markova SM, Chinn LW et al. Very important pharmacogene summary: ABCB1 (MDR1, P-glycoprotein). Pharmacogenet. Genomics 21(3), 152-161 (2011).

18. Tang K, Ngoi S-M, Gwee P-C et al. Distinct haplotype profiles and strong linkage disequilibrium at the MDR1 multidrug transporter gene locus in three ethnic Asian populations. Pharmacogenetics 12(6), 437-450 (2002).

19. Kim RB, Leake BF, Choo EF et al. Identification of functionally variant MDR1 alleles among European Americans and African Americans. Clin. Pharmacol. Ther. 70(2), 189-199 (2001).

20. Chen C-C, Huang C-H, Wu M-TM et al. Multidrug resistance 1 gene variants, pesticide exposure, and increased risk of DNA damage. Biomed. Res. Int. 2014, 965729 (2014).

21. Tsai S-M, Lin C-Y, Wu S-H et al. Side effects after docetaxel treatment in Taiwanese breast cancer patients with CYP3A4, CYP3A5, and ABCB1 gene polymorphisms. Clin. Chim. Acta 404(2), 160-165 (2009). 
22. Jabir RS, Ho GF, Annuar MaBA, Stanslas J. Association of allelic interaction of single nucleotide polymorphisms of influx and efflux transporters genes with nonhematologic adverse events of docetaxel in breast cancer patients. Clin. Breast Cancer 18(5), e1173-e1179 (2018).

23. Tulsyan S, Chaturvedi P, Singh AK et al. Assessment of clinical outcomes in breast cancer patients treated with taxanes: multi-analytical approach. Gene 543(1), 69-75 (2014).

24. Chang H, Rha SY, Jeung HC et al. Association of the $A B C B 1$ gene polymorphisms $2677 \mathrm{G}>\mathrm{T} / \mathrm{A}$ and $3435 \mathrm{C}>\mathrm{T}$ with clinical outcomes of paclitaxel monotherapy in metastatic breast cancer patients. Ann. Oncol. 20(2), 272-277 (2009).

25. Ikeda M, Tsuji D, Yamamoto $\mathrm{K}$ et al. Relationship between $A B C B 1$ gene polymorphisms and severe neutropenia in patients with breast cancer treated with doxorubicin/cyclophosphamide chemotherapy. Drug Metabol. Pharmacokinet. 30(2), 149-153 (2015).

26. Wu H, Kang H, Liu Y et al. Roles of $A B C B 1$ gene polymorphisms and haplotype in susceptibility to breast carcinoma risk and clinical outcomes. J. Cancer Res. Clin. Oncol. 138(9), 1449-1462 (2012).

27. Lal S, Wong ZW, Sandanaraj E et al. Influence of $A B C B 1$ and $A B C G 2$ polymorphisms on doxorubicin disposition in Asian breast cancer patients. Cancer Sci. 99(4), 816-823 (2008).

28. Chaturvedi P, Tulsyan S, Agarwal G et al. Influence of $A B C B 1$ genetic variants in breast cancer treatment outcomes. Cancer Epidemiol. 37(5), 754-761 (2013).

29. Priyadarshini R, Raj GM, Kayal S, Ramesh A, Shewade DG. Influence of $A B C B 1$ C3435T and C1236T gene polymorphisms on tumour response to docetaxel-based neo-adjuvant chemotherapy in locally advanced breast cancer patients of South India. J. Clin. Pharm. Ther. 44(2), 188-196 (2019).

30. Eckhoff L, Feddersen S, Knoop AS, Ewertz M, Bergmann TK. Docetaxel-induced neuropathy: a pharmacogenetic case-control study of 150 women with early-stage breast cancer. Acta Oncol. 54(4), 530-537 (2015).

31. Tanabe Y, Shimizu C, Hamada A et al. Paclitaxel-induced sensory peripheral neuropathy is associated with an $A B C B 1$ single nucleotide polymorphism and older age in Japanese. Cancer Chemother. Pharmacol. 79(6), 1179-1186 (2017).

32. Lévy $\mathrm{P}$, Gligorov J, Antoine $\mathrm{M}$ et al. Influence of $A B C B 1$ polymorphisms and docetaxel pharmacokinetics on pathological response to neoadjuvant chemotherapy in breast cancer patients. Breast Cancer Res. Treat. 139(2), 421-428 (2013).

33. Fajac A, Gligorov J, Rezai K et al. Effect of $A B C B 1 \mathrm{C} 3435 \mathrm{~T}$ polymorphism on docetaxel pharmacokinetics according to menopausal status in breast cancer patients. Br. J. Cancer 103(4), 560-566 (2010).

34. Cizmarikova M, Wagnerova M, Schonova L et al. MDR1 (C3435T) polymorphism: relation to the risk of breast cancer and therapeutic outcome. Pharmacogenomics J. 10(1), 62-69 (2010).

35. Ji M, Tang J, Zhao J, Xu B, Qin J, Lu J. Polymorphisms in genes involved in drug detoxification and clinical outcomes of anthracycline-based neoadjuvant chemotherapy in Chinese Han breast cancer patients. Cancer Biol. Ther. 13(5), 264-271 (2012).

36. Kim K-P, Ahn J-H, Kim S-B et al. Prospective evaluation of the drug-metabolizing enzyme polymorphisms and toxicity profile of docetaxel in Korean patients with operable lymph node-positive breast cancer receiving adjuvant chemotherapy. Cancer Chemother. Pharmacol. 69(5), 1221-1227 (2012).

37. Sensorn I, Sirachainan E, Chamnanphon M et al. Association of CYP3A4/5, ABCB1 and $A B C C 2$ polymorphisms and clinical outcomes of Thai breast cancer patients treated with tamoxifen. Pharmacogenomics Pers. Med. 6, 93-98 (2013).

38. Kus T, Aktas G, Kalender ME et al. Polymorphism of CYP3A4 and $A B C B 1$ genes increase the risk of neuropathy in breast cancer patients treated with paclitaxel and docetaxel. Oncotargets Ther. 9, 5073-5080 (2016).

39. Kim H-J, Im S-A, Keam B et al. $A B C B 1$ polymorphism as prognostic factor in breast cancer patients treated with docetaxel and doxorubicin neoadjuvant chemotherapy. Cancer Sci. 106(1), 86-93 (2015).

40. Argalacsova S, Slanar O, Vitek P et al. Contribution of $A B C B 1$ and CYP2D6 genotypes to the outcome of tamoxifen adjuvant treatment in premenopausal women with breast cancer. Physiol. Res. 64(Suppl. 4), S539-547 (2015).

41. Gervasini G, Jara C, Olier C, Romero N, Martínez R, Carrillo JA. Polymorphisms in $A B C B 1$ and CYP19A1 genes affect anastrozole plasma concentrations and clinical outcomes in postmenopausal breast cancer patients. Br. J. Clin. Pharmacol. 83(3), 562-571 (2017).

42. Abraham JE, Guo Q, Dorling L et al. Replication of genetic polymorphisms reported to be associated with taxane-related sensory neuropathy in patients with early breast cancer treated with Paclitaxel. Clin. Cancer Res. 20(9), 2466-2475 (2014).

43. Leschziner GD, Andrew T, Pirmohamed M, Johnson MR. ABCB1 genotype and PGP expression, function and therapeutic drug response: a critical review and recommendations for future research. Pharmacogenomics J. 7(3), 154-179 (2007).

44. Wolking S, Schaeffeler E, Lerche H, Schwab M, Nies AT. Impact of genetic polymorphisms of $A B C B 1$ (MDR1, P-glycoprotein) on drug disposition and potential clinical implications: update of the literature. Clin. Pharmacokinet. 54(7), 709-735 (2015).

45. Kimchi-Sarfaty C, Oh JM, Kim I-W et al. A “silent” polymorphism in the MDR1 gene changes substrate specificity. Science 315(5811), 525-528 (2007).

46. Vulsteke C, Lambrechts D, Dieudonné A et al. Genetic variability in the multidrug resistance associated protein-1 (ABCC1/MRP1) predicts hematological toxicity in breast cancer patients receiving (neo-)adjuvant chemotherapy with 5-fluorouracil, epirubicin and cyclophosphamide (FEC). Ann. Oncol. 24(6), 1513-1525 (2013). 
47. Pfeil AM, Vulsteke C, Paridaens R et al. Multivariable regression analysis of febrile neutropenia occurrence in early breast cancer patients receiving chemotherapy assessing patient-related, chemotherapy-related and genetic risk factors. BMC Cancer 14(1), 201-211 (2014).

48. Wojnowski L, Kulle B, Schirmer $\mathrm{M}$ et al. $\mathrm{NAD}(\mathrm{P}) \mathrm{H}$ oxidase and multidrug resistance protein genetic polymorphisms are associated with doxorubicin-induced cardiotoxicity. Circulation 112(24), 3754-3762 (2005).

49. Reichwagen A, Ziepert M, Kreuz M et al. Association of NADPH oxidase polymorphisms with anthracycline-induced cardiotoxicity in the RICOVER-60 trial of patients with aggressive CD20 + B-cell lymphoma. Pharmacogenomics 16(4), 361-372 (2015).

50. Semsei AF, Erdelyi DJ, Ungvari I et al. ABCC1 polymorphisms in anthracycline-induced cardiotoxicity in childhood acute lymphoblastic leukaemia. Cell Biol. Int. 36(1), 79-86 (2012).

51. Kiyotani K, Mushiroda T, Imamura CK et al. Significant effect of polymorphisms in CYP2D6 and ABCC2 on clinical outcomes of adjuvant tamoxifen therapy for breast cancer patients. J. Clin. Oncol. 28(8), 1287-1293 (2010).

52. Xiao Q, Zhou Y, Winter $S$ et al. Germline variant burden in multidrug resistance transporters is a therapy-specific predictor of survival in breast cancer patients. Int. J. Cancer 146(9), 2475-2487 (2020).

53. Huisman MT, Chhatta AA, Van Tellingen O, Beijnen JH, Schinkel AH. MRP2 (ABCC2) transports taxanes and confers paclitaxel resistance and both processes are stimulated by probenecid. Int. J. Cancer 116(5), 824-829 (2005).

54. Elens L, Tyteca D, Panin N et al. Functional defect caused by the 4544G >A SNP in ABCC2. Pharmacogenet. Genomics 21(12), 884-893 (2011).

55. Arlanov R, Porter A, Strand D et al. Functional characterization of protein variants of the human multidrug transporter $A B C C 2$ by a novel targeted expression system in fibrosarcoma cells. Hum. Mutat. 33(4), 750-762 (2012).

56. Wu $\mathrm{H}$, Liu Y, Kang $\mathrm{H}$ et al. Genetic variations in $A B C G 2$ gene predict breast carcinoma susceptibility and clinical outcomes after treatment with anthracycline-based chemotherapy. Biomed Res. Int. 2015, 279109 (2015).

57. Kim H-S, Sunwoo YE, Ryu J-Y et al. The effect of ABCG2 V12M, Q141K and Q126X, known functional variants in vitro, on the disposition of lamivudine. Br. J. Clin. Pharmacol. 64(5), 645-654 (2007).

58. Zámbó B, Mózner $\mathrm{O}$, Bartos $\mathrm{Z}$ et al. Cellular expression and function of naturally occurring variants of the human $A B C G 2$ multidrug transporter. Cell. Mol. Life Sci. 77(2), 365-378 (2020).

59. Imai $\mathrm{Y}$, Nakane $\mathrm{M}$, Kage $\mathrm{K}$ et al. C421A polymorphism in the human breast cancer resistance protein gene is associated with low expression of Q141K protein and low-level drug resistance. Mol. Cancer Ther. 1(8), 611-616 (2002).

60. Kondo C, Suzuki H, Itoda M et al. Functional analysis of SNPs variants of BCRP/ABCG2. Pharm. Res. 21(10), 1895-1903 (2004).

61. Hu M, To KKW, Mak VWL, Tomlinson B. The $A B C G 2$ transporter and its relations with the pharmacokinetics, drug interaction and lipid-lowering effects of statins. Expert Opin. Drug Metabol. Toxicol. 7(1), 49-62 (2011).

62. Nakanishi T, Ross DD. Breast cancer resistance protein (BCRP/ABCG2): its role in multidrug resistance and regulation of its gene expression. Chin. J. Cancer 31(2), 73-99 (2012).

63. Kanzaki A, Toi M, Nakayama $\mathrm{K}$ et al. Expression of multidrug resistance-related transporters in human breast carcinoma. Jpn J. Cancer Res. 92(4), 452-458 (2001).

64. Burger H, Foekens JA, Look MP et al. RNA expression of breast cancer resistance protein, lung resistance-related protein, multidrug resistance-associated proteins 1 and 2, and multidrug resistance gene 1 in breast cancer: correlation with chemotherapeutic response. Clin. Cancer Res. 9(2), 827-836 (2003).

65. Stacy AE, Jansson PJ, Richardson DR. Molecular pharmacology of ABCG2 and its role in chemoresistance. Mol. Pharmacol. 84(5), 655-669 (2013).

66. Honjo Y, Hrycyna CA, Yan QW et al. Acquired mutations in the $M X R / B C R P / A B C P$ gene alter substrate specificity in MXR/BCRP/ABCP-overexpressing cells. Cancer Res. 61(18), 6635-6639 (2001).

67. Allen JD, Jackson SC, Schinkel AH. A mutation hot spot in the Bcrp1 (Abcg2) multidrug transporter in mouse cell lines selected for Doxorubicin resistance. Cancer Res. 62(8), 2294-2299 (2002).

68. Low S-K, Kiyotani K, Mushiroda T, Daigo Y, Nakamura Y, Zembutsu H. Association study of genetic polymorphism in $A B C C 4$ with cyclophosphamide-induced adverse drug reactions in breast cancer patients. J. Hum. Genet. 54(10), 564-571 (2009).

69. Lal S, Sutiman N, Ooi LL et al. Pharmacogenetics of ABCB5, ABCC5 and RLIP76 and doxorubicin pharmacokinetics in Asian breast cancer patients. Pharmacogenomics J. 17(4), 337-343 (2017).

70. Awada Z, Haider S, Tfayli A et al. Pharmacogenomics variation in drug metabolizing enzymes and transporters in relation to docetaxel toxicity in Lebanese breast cancer patients: paving the way for OMICs in low and middle income countries. OMICS 17(7), 353-367 (2013).

71. Tian Q, Zhang J, Tan TMC et al. Human multidrug resistance associated protein 4 confers resistance to camptothecins. Pharm. Res. 22(11), 1837-1853 (2005).

72. Kanamitsu K, Kusuhara H, Schuetz JD, Takeuchi K, Sugiyama Y. Investigation of the importance of multidrug resistance-associated protein 4 (Mrp4/Abcc4) in the active efflux of anionic drugs across the blood-brain barrier. J. Pharm. Sci. 106(9), 2566-2575 (2017). 
73. Magdy T, Burmeister BT, Burridge PW. Validating the pharmacogenomics of chemotherapy-induced cardiotoxicity: what is missing? Pharmacol. Ther. 168, 113-125 (2016).

74. Teft WA, Mansell SE, Kim RB. Endoxifen, the active metabolite of tamoxifen, is a substrate of the efflux transporter P-glycoprotein (multidrug resistance 1). Drug Metab. Dispos. 39(3), 558-562 (2011).

75. Iusuf D, Teunissen SF, Wagenaar E, Rosing H, Beijnen JH, Schinkel AH. P-glycoprotein $(A B C B 1)$ transports the primary active tamoxifen metabolites endoxifen and 4-hydroxytamoxifen and restricts their brain penetration. J. Pharmacol. Exp. Ther. 337(3), 710-717 (2011).

76. Jiang Z-P, Wang Y-R, Xu P, Liu R-R, Zhao X-L, Chen F-P. Meta-analysis of the effect of MDR1 C3435T polymorphism on cyclosporine pharmacokinetics. Basic Clin. Pharmacol. Toxicol. 103(5), 433-444 (2008).

77. Haerian BS, Lim K-S, Tan CT, Raymond AA, Mohamed Z. Association of $A B C B 1$ gene polymorphisms and their haplotypes with response to antiepileptic drugs: a systematic review and meta-analysis. Pharmacogenomics 12(5), 713-725 (2011).

78. Drescher S, Schaeffeler E, Hitzl M et al. MDR1 gene polymorphisms and disposition of the P-glycoprotein substrate fexofenadine. Br. J. Clin. Pharmacol. 53(5), 526-534 (2002).

79. Chowbay B, Li H, David M, Cheung YB, Lee EJD. Meta-analysis of the influence of MDR1 C3435T polymorphism on digoxin pharmacokinetics and MDR1 gene expression. Br. J. Clin. Pharmacol. 60(2), 159-171 (2005).

80. Rudin CM, Liu W, Desai A et al. Pharmacogenomic and pharmacokinetic determinants of erlotinib toxicity. J. Clin. Oncol. 26(7), 1119-1127 (2008)

81. Petain A, Kattygnarath D, Azard J et al. Population pharmacokinetics and pharmacogenetics of imatinib in children and adults. Clin. Cancer Res. 14(21), 7102-7109 (2008).

82. Lemos C, Giovannetti E, Zucali PA et al. Impact of $A B C G 2$ polymorphisms on the clinical outcome and toxicity of gefitinib in non-small-cell lung cancer patients. Pharmacogenomics 12(2), 159-170 (2011).

83. Dehghan A, Köttgen A, Yang Q et al. Association of three genetic loci with uric acid concentration and risk of gout: a genome-wide association study. Lancet 372(9654), 1953-1961 (2008).

84. Matsuo $\mathrm{H}$, Takada $\mathrm{T}$, Ichida $\mathrm{K}$ et al. Common defects of $A B C G 2$, a high-capacity urate exporter, cause gout: a function-based genetic analysis in a Japanese population. Sci. Transl. Med. 1(5), 5ra11-15ra11 (2009).

85. Brant SR, Panhuysen CIM, Nicolae D et al. MDR1 Ala893 polymorphism is associated with inflammatory bowel disease. Am. J. Hum. Genet. 73(6), 1282-1292 (2003).

86. Dessilly G, Panin N, Elens L, Haufroid V, Demoulin J-B. Impact of $A B C B 1$ 1236C $>$ T-2677G $>$ T-3435C $>$ T polymorphisms on the anti-proliferative activity of imatinib, nilotinib, dasatinib and ponatinib. Sci. Rep. 6(1), 29559 (2016).

87. Hung C-C, Chen C-C, Lin C-J, Liou H-H. Functional evaluation of polymorphisms in the human $A B C B 1$ gene and the impact on clinical responses of antiepileptic drugs. Pharmacogenet. Genomics 18(5), 390-402 (2008).

88. Salama NN, Yang Z, Bui T, Ho RJY. MDR1 haplotypes significantly minimize intracellular uptake and transcellular P-gp substrate transport in recombinant LLC-PK1 cells. J. Pharm. Sci. 95(10), 2293-2308 (2006).

89. Jungsuwadee P, Zhao T, Stolarczyk EI et al. The G671V variant of MRP1/ABCC1 links doxorubicin-induced acute cardiac toxicity to disposition of the glutathione conjugate of 4-hydroxy-2-trans-nonenal. Pharmacogenet. Genomics 22(4), 273-284 (2012).

90. Conseil G, Cole SPC. Two polymorphic variants of $A B C C 1$ selectively alter drug resistance and inhibitor sensitivity of the multidrug and organic anion transporter multidrug resistance protein 1. Drug Metab. Dispos. 41(12), 2187-2196 (2013).

91. Fujikura K, Ingelman-Sundberg M, Lauschke VM. Genetic variation in the human cytochrome P450 supergene family. Pharmacogenet. Genomics 25(12), 584-594 (2015).

92. Gordon AS, Tabor HK, Johnson AD et al. Quantifying rare, deleterious variation in 12 human cytochrome $\mathrm{P} 450$ drug-metabolism genes in a large-scale exome dataset. Hum. Mol. Genet. 23(8), 1957-1963 (2014).

93. Schaller L, Lauschke VM. The genetic landscape of the human solute carrier (SLC) transporter superfamily. Hum. Genet. 138(11-12), 1359-1377 (2019).

94. Zhang B, Lauschke VM. Genetic variability and population diversity of the human SLCO (OATP) transporter family. Pharmacol. Res. 139, 550-559 (2019).

95. Kozyra M, Ingelman-Sundberg M, Lauschke VM. Rare genetic variants in cellular transporters, metabolic enzymes, and nuclear receptors can be important determinants of interindividual differences in drug response. Genet. Med. 19(1), 20-29 (2017).

96. Lauschke VM, Ingelman-Sundberg M. Precision medicine and rare genetic variants. Trends Pharmacol. Sci. 37(2), 85-86 (2016).

97. Lauschke VM, Ingelman-Sundberg M. How to consider rare genetic variants in personalized drug therapy. Clin. Pharmacol. Ther. 103(5), 745-748 (2018). 